\title{
Kompozit Yüzey Plakalı ve Alüminyum Çekirdekli Sandviç Levhaların Balistik Performanslarının Sonlu Elemanlar Analiz Yöntemi ile İncelenmesi
}

\author{
Murat Yazıcı1 ${ }^{1}$, Yalçın Boztoprak ${ }^{2 *}$, Saime Uygun ${ }^{3}$ \\ ${ }^{1}$ Bursa Uludağ Üniversitesi, Mühendislik Fakültesi, Otomotiv Mühendisliği Bölümü, Bursa, Türkiye (ORCID: 0000-0002-8720-7594) \\ ${ }^{2}$ Marmara Üniversitesi Teknoloji Fakültesi Metalurji ve Malzeme Mühendisliği Bölümü, İstanbul, Türkiye (ORCID: 0000-0003-1714-7394) \\ ${ }^{3}$ Bursa Uludağ Üniversitesi, Mühendislik Fakültesi, Otomotiv Mühendisliği Bölümü, Bursa, Türkiye (ORCID: 0000-0003-3784-3717)
}

(İlk Geliş Tarihi 23 Eylül 2021 ve Kabul Tarihi 12 Aralık 2021)

(DOI: 10.31590 /ejosat.999576)

ATIF/REFERENCE: Yazıcı, M., Boztoprak, Y. \& Uygun, S. (2021). Kompozit Yüzey Plakalı ve Alüminyum Çekirdekli Sandviç Levhaların Balistik Performanslarının Sonlu Elemanlar Analiz Yöntemi ile İncelenmesi. Avrupa Bilim ve Teknoloji Dergisi, (31), 933942.

\section{Öz}

Bu çalışmada ön ve arka kısımları kompozit yüzey plakalı sandviç bir levhanın balistik özellikleri sayısal analizler ile incelenmiştir. Tasarlanan balistik koruyucu malzeme ön ve arka plakaları karbon-aramid takviyeli epoksi kompozit malzemeden, çekirdek ise yüksek plastik şekil değiştirme özelliği ve hafif olması nedeniyle alüminyum (Al5083 H116) plakadan oluşturulmuştur. Gerçekleştirilen bu tasarımda amaç; kompozit malzemenin enerji sönümleme mekanizmalarını kullanarak ön kompozit plakada mermi enerjisinin düşürülmesi, orta alüminyum plakanın plastik deformasyon, sürtünme kabiliyetinden yararlanma ve arka kompozit plakada ise merminin nihai enerjisinin yayılarak tamamen yok edilmesi şeklindedir. Öncelikle mermi hareketi, hesaplamalı akışkanlar analizleri (CFD) ile incelenmiştir. CFD yardımıyla namlu ucundan $5 \mathrm{~m}$ uzaktaki hedef plaka yüzeyine temas hızı hava sürtünmesi dikkate alınarak yeniden hesaplanmıştır. Mach sayısına göre değişen direnç katsayısı değerleri incelendiğinde CFD analizleri ile elde edilen sonuçlara göre $5 \mathrm{~m}$ mesafeden yapılan bir atışta, namludan çıkan mermi çıkış hızı ile koruyucu malzeme yüzeyine mermi temas hızı arasındaki hava sürtünmesinden kaynaklanan azalma ihmal edilebilir. Bu çalışmada, kompozit plakaların ilavesi ile balistik özellikleri artırılmış kompozit-metal hibrit çok katmanlı sandviç levhanın balistik performansları, NIJ 0108.01 standardı test prosedürüne göre LS DYNA ${ }^{\circledR}$ yazılımı ile dinamik/eksplisit analizler gerçekleştirilerek nümerik olarak incelenmiştir. Mermi olarak 9x19 mm 8 gram ağırlığındaki Parabellum FMJ (Full Metal Jacket) fişek seçilmiş ve farklı mermi hızlarında analizler gerçekleştirilmiştir. Kompozit plaka için malzeme kartı olarak MAT 22 malzeme kartı uygulanırken, hasar modeli olarak MAT59 kartı kullanılmıştır. Merminin herhangi bir deformasyona uğramayıp malzeme üzerinde meydana getirdiği hasarı gözlemlemek amacıyla mermi çekirdeği malzemesi için MAT 20 (MAT_RIGID) malzeme modeli kullanılmış ve çelik malzeme tanımı yapılmıştır. Yapılan simülasyonlar sonucunda tasarlanan kompozit plakalı sandviç panelin NIJ II-A ve NIJ II standardına göre mermi tarafından delinemediği ve balistik koruyucu malzeme olabileceği gösterilmiştir.

Anahtar Kelimeler: Sonlu Elemanlar Analizi, Balistik Koruma, karbon-aramid/epoksi kompozit, kompozit-metal hibrit sandviç yapı

\section{Investigation of Ballistic Performance of Composite Sandwich Plates with Aluminum Core by Finite Element Analysis Method}

\begin{abstract}
The numerical analysis of the ballistic properties of a sandwich plate with composite surface sheets on the front and back was used in this study. The front and back sheets of the designed ballistic protective material are made of carbon-aramid reinforced epoxy composite material, while the core is made of aluminum (A15083 H116) plate, which has a high plastic deformation and is lightweight. The aim of this design is; The aim is to reduce the bullet energy in the front composite plate by using the energy absorption mechanisms of the composite material, to benefit from the plastic deformation and friction ability of the middle aluminum plate, and to completely destroy the final energy of the bullet by spreading in the rear composite plate. First of all, the projectile motion was investigated by computational fluid dynamics (CFD). With the help of CFD, the contact velocity with the target plate surface $5 \mathrm{~m}$ away from the muzzle was recalculated considering the air drag. When the drag coefficient values varying according to the Mach number are examined, according to the results obtained by CFD analysis, the decrease caused by the air friction between the bullet exit velocity from the barrel and the
\end{abstract}

* Sorumlu Yazar: Marmara Üniversitesi, Teknoloji Fakültesi, Metalurji ve Malzeme Mühendisliği Bölümü, İstanbul, Türkiye, ORCID: 0000-0003-

1714-7394, yboztoprak@marmara.edu.tr 
bullet contact speed with the protective material surface can be neglected in a shot made from a distance of $5 \mathrm{~m}$. In this study, the ballistic performances of composite-metal hybrid multi-layer sandwich plate with increased ballistic properties by adding composite plates were numerically investigated by performing dynamic/explicit analyses with LS DYNA® software according to the NIJ 0108.01 procedure. The bullet was selected from the Parabellum FMJ (Full Metal Jacket) cartridge, which measures 9x19 mm and weighs 8 grams, and analyses were conducted at various bullet velocities. While the MAT 22 material card was used as the material card for the composite plate, the MAT59 damage model was used. The bullet's material was modeled using the MAT 20 (MAT RIGID) material model, and a steel material definition was created to evaluate the developed composite-metal hybrid laminated sandwich panel's damage as a ballistic protective material. The simulations demonstrate that the designed composite-metal hybrid laminated sandwich panel cannot be pierced by a bullet in accordance with the NIJ II-A and NIJ II standards and thus can be used as a ballistic protective material.

Keywords: Finite Element Analysis, Ballistic Protection, carbon-aramid/epoxy composite, composite-metal hybrid sandwich structure

\section{Giriş}

Patlama dalgaları ve mühimmat patlamasının ürettiği enkaz dahil olmak üzere ilgili parçalanma, askeri operasyon ortamlarında yüksek zayiat vermeye devam ediyor. Son birkaç on yılda, malzeme ve sistemlerin patlama dalgası ve mermi etkilerine karşı koruyucu performansı üzerine araştırmalar yapılmıştır (Tan, 2013).

Mühimmat tehditlerinin sürekli olarak gelişip çeşitlenmesi, zırhlı araç teknolojisinin ve personel koruma sistemlerinin bu ilerleme karşısında başarılı olabilmesi için geliştirme çalışmalarını zorunlu kılmıştır. Günümüzde zırhlı araçlar, içerisindeki personeli korurken araç performansını olumsuz etkilemeyecek hafif ve mukavim gelişmiş zırh sistemlerine ihtiyaç vardır. Yine kişisel koruyucu ekipman tasarımında da hedeflenen koruma sağlanırken personeli yavaşlatmayacak ve hareketini kısıtlamayacak kişisel zırh sistemleri gereksinimi dikkate alınmaktadır (Oliveira vd., 2021; Reis vd., 2021) Bu gereksinimlerin karşılanması adına mukavemet özelliklerinden ödün vermeden daha hafif malzemelerin kullanılması zorunlu hale gelmiştir.

Kompozit malzemeler; farklı malzemelerin kendine has üstün özelliklerinin bir araya getirilip tek başına kullanılan malzemelerden daha üstün yeni bir yapı oluşturulmasına olanak verir. Hafiflik ve mukavemetin önemli olduğu, birbirine tezat fonksiyonlar1 yerine getirmesi beklenen komponentlerde kompozit malzemelerin kullanımı önemlidir ve yaygındır. Özellikle hafifliğin ön planda tutulduğu havacılık ve otomotiv sektöründe, personel ve araç zırhı geliştirilmesi açısından savunma sanayisinde sıklıkla tercih edilirler ve kullanım alanlarını genişletmek için çalışmalar sürdürülmektedir (Bitlisli ve Yazıc1, 2019).

Yanen ve Solmaz, tabakalı hibrit kompozitlerin bireysel zirh malzemesi olarak kullanılabilirliğini deneysel olarak araştırmışlardır. Çalışma kapsamında farklı fỉber takviye açılarına, farklı tabaka sayılarına ve farklı kalınlıklara sahip cam fiber/aramid fiber/karbon fiber tabakalı kompozit plakaların balistik deneyleri yapılmış ve sonuçları incelenmiştir. Bu amaçla 200x200mm boyutlarındaki 30 tabakalı farklı kalınlıkta 4 adet plaka, elle yatırma yöntemi kullanılarak üretilmiştir. Farklı fiber takviye açılarının balistik performansının incelenebilmesi için $0^{\circ}$, $45^{\circ}$, plain dokuma ve twill örgü kumaşlar kullanılmıştır. Sonuçlar değerlendirildiğinde balistik testlerde en başarılı olan numunenin en ağır ve en kalın numune olan $\left[\operatorname{Cam}\left(45^{\circ}\right)_{10} / \text { Aramid(Plain }\right)_{10} /$ Karbon $\left.\left(45^{\circ}\right)_{10}\right]$ dizilimine sahip numunenin değil, $[\text { Cam(Twill) })_{10} /$ Aramid(Plain) ${ }_{10} /$ Karbon(Twill) $\left.)_{10}\right]_{\text {dizilimli }}$ olan numune olduğu tespit edilmiştir. $\mathrm{Bu}$ sonuçlar neticesinde twill dokuma yapısına sahip kumaşların balistik dayanımının daha iyi olduğu ortaya çıkmıştır (Yanen ve Solmaz, 2015)
Sabah (2018), zırhlı araçlarda patlama ve balistik saldırılar sonucunda araç içinde meydana gelen parçaçık saçılmalarını azaltmaya ve tutmaya yönelik olarak kullanılabilecek çelik tel örgü takviyeli ve takviyesiz aramid kompozit tabakaların üretimi ve balistik performanslarının deneysel olarak incelenmesi üzerine çalışmıştır. Vakum infüzyon yöntemiyle başarıyla gerçekleştirilen tabaka üretimlerinde balistik özellikleri ile ön plana çıkan Twaron T750 aramid kumaşı kullanılmıştır. Çelik tel örgü takviyesi olarak ise mesh tipi ve tel çapları farklı olan iki farklı tipte AISI 304 kalite tel örgü kullanılmıştır. Testler, balistik test laboratuvar ortamında MIL-STD-662F V50 ve STANAG 2920 standartlarında yapılmıştır. Testlerde öncelikle tel örgü içermeyen numunenin, ardından tel örgü içeren 3 farklı numunenin V50 balistik hız limitleri bulunarak enerji sönümleme kapasiteleri hesaplanmıştır. Sonuçta çelik tel örgü takviyesi içermeyen numune 1'in enerji sönümleme kapasitesi, üretilen tabaka bazında $107,01 \mathrm{j}$, alansal yoğunluğa göre ise $16,59 \mathrm{jm}^{2} / \mathrm{kg}$ olarak bulunmuştur. Tabaka bazında $168,89 \mathrm{j}$ ile en iyi 2 . balistik dayanıma sahip olduğunu gösteren numune 2, aynı zamanda alansal yoğunluğa göre de $18,65 \mathrm{jm}^{2} / \mathrm{kg}$ ile en iyi balistik performansı sergilemiştir. Tabaka bazında $180,11 \mathrm{j}$ ile en iyi balistik dayanıma sahip olan numune 3 ise alansal yoğunluğuna göre $15,78 \mathrm{jm}^{2} / \mathrm{kg}$ ile en kötü performansı göstermiştir. Numune 4 ise numune 2'ye yakın özellikler göstermiştir. Böylece çelik tel örgü takviyesinin balistik dayanım özelliklerine etkileri ortaya konulmuştur (Sabah, 2018).

Berk (2014), yürüttüğü çalışmada yüksek hızda darbe uygulamalarında takviye tipinin etkisini ve farklı nümerik kompozit hasar modellerini incelemiştir. Kompozit plakalarda aramid/epoksi ve karbon-aramid/epoksi kompozitler çalışılmıştır. Enerji sönümleme mekanizmaları hem deneysel hem de nümerik yöntemlerle, her iki kompozit malzeme için 6 farklı mermi hızı kullanılmıştır. Nümerik çalışmada ANSYS yazılımı ön işlemci olarak, LS-DYNA ${ }^{\circledR}$ ise çözücü olarak kullanılmış ve LS DYNA ${ }^{\circledR}$ üzerinden yapılan modellemede kompozit malzemeler için MAT 22 (Mat_Composite_Damage) ve MAT 59 (Mat_Composite_Failure_Solid_Model) olmak üzere 2 farklı malzeme modeli ìle simülasyon gerçekleştirildiği görülmektedir. Tabakalı kompozit modeli ve MAT 22, tabakalı kompozit modeli ve MAT 59 ve tek tabakalı kompozit modeli ve MAT 59 şeklinde 3 farklı nümerik modelin analiz edildiği bir çalışmadır. Kompozit malzeme içerisinde kullanılan kumaş takviyelerin örgü yapısından dolayı basitleştirilmiş bir model olarak, katmanlardan oluştuğu kabul edilmiş ve delaminasyon modellenmesi için kompozit tabakalar arasında ayrılma özelliğine sahip kontak mekanizması tanımlandığı görülmektedir. Balistik limit hız açısından tabakalı kompozitlerin daha iyi sonuç verdiği ve limit hızı arttırdığı gözlemlenmiştir. Karbon-aramid/ epoksi kompozitler için tabakalı modellemede en yüksek 2 mermi hızında MAT 22 malzeme modeli daha iyi sonuç verirken, en düşük 2 hız için MAT 59 malzeme kartının daha iyi sonuç verdiği 
anlaşılmaktadır. Nümerik ve deneysel çalışma arasında iyi bir uyum yakalanmıştır (Berk, 2014).

Yapılan bir çalışmada çok duvarlı karbon nanotüp (MWCNT) ve cam baloncuk dolgu maddeleri ile sönümleme özellikleri geliştirilmiş iki farklı kauçuk karışımının cam bilyeler ile takviye edilerek yapısal mukavemeti yüksek AA7075-T651 alüminyum levhalar arasında kürlenmesiyle elde edilen koruyucu zırh levhalarının (KZL) balistik davranışı incelenmiştir. Bu çalışmada iki farklı sönümleme özelliğine sahip kauçuk matris malzemesi kullanılarak 27, 30 ve 35 mm yüksekliklerinde toplam 6 adet KZL hazırlanmıştır. Çok duvarlı karbon nanotüplerle hazırlanan KZL'lerin balistik performansının cam baloncuklarla hazırlananlara göre daha iyi olduğu belirlenmiştir. MWCNT'lerin üstün mekanik özellikleri ve yüksek en boy oranı sayesinde, hazırlanan sönümleme kauçuk matrislerin penetrasyon ve şişme yüksekliklerinde cam baloncuklara kıyasla mükemmel sonuçlar elde edildiği anlaşılmaktadır. MWCNT'ler ile hazırlanan KZL'lerin kalınlığının artmasıyla merminin ön ve arka yüzeylerde oluşturduğu penetrasyon derinliği ve çıkıntı yüksekliğinin deformasyon etkisi azalmıştır. KZL kalınlığı 27 mm'den 35 mm'ye yükseldikçe penetrasyon derinliği \%38, çıkıntı yüksekliği ise \%35 azaldığı görülmektedir. Cam baloncuklarla dolgulu kauçuk kullanılarak KZL'lerde penetrasyon ve şişme miktarı arttı. Plaka kalınlığı arttıkça sönümleme özelliği azaldı ve cam bilyeler aktive olduğu için mermin KZL içerisinde tamamen durdurulduğu görülmüştür (Kasım, 2021).

Kişisel koruma uygulamaları amacıyla geliştirilmiş yumuşak köpük ve hava boşluğu sistemlerinin değerlendirilmesi için Ouellet ve diğerleri tarafından bir patlama odası testi yapılmıştır. Hava boşluğu üzerinde sert bir malzeme ve sıkıştırılabilir bir köpük veya sert bir levhadan oluşan bir istifleme kullanılarak aşırı patlama basıncının azaltılabileceğini belirtmişlerdir (Ouellet, S. $\mathrm{vd}, 2008)$.

Bir başka çalışma ise alüminyum-kauçuk kompozit levhanın darbe yüklemesi altındaki performansını araştırmayı amaçlamaktadır. Plakanın darbe direnci hem deneysel hem de sayısal yöntemler kullanılarak değerlendirilmiştir. Deneysel testler, gaz tabancası kullanılarak 75, 101, 144 ve 168 m/s hızlarda gerçekleştirilmiştir. Kauçuk tabakanın, alüminyum levhanın ön yüzünde veya arka yüzünde konumlandırılmasının etkisini değerlendirmişlerdir. Ön yüzünde kauçuk olan kompozit plakanın enerjiyi emmek için daha yüksek performans sağladığı tespit edilmiştir. Deneye paralel olarak, alüminyum-kauçuk kompozit levhanın yüksek enerji oranlı yükleme koşulu altında tepkisini simüle etmek için sonlu eleman yazılımı LS-DYNA ${ }^{\circledR}$ kullanarak bir sonlu eleman modeli oluşturmuşlardır. Sonlu eleman modellemesinden elde edilen veriler, kırılma mekanizması ve enerji absorpsiyonu açısından deneysel sonuçlarla yakın bir uyum göstermiştir. Ayrıca farklı darbe hızları, kauçuk formülasyonu, kauçuk katman kalınlığı, kauçuk ve alüminyum katmanlar arasındaki ara yüzey bağlanma kuvveti ve alüminyum-kauçuk sandviç panelin balistik performansını içeren parametrik bir çalışma yapmışlardır. Kauçuk tabakanın kalınlığının arttırılmasıyla, özellikle kauçuk tabaka alüminyum levhanın önüne yerleştirildiğinde kompozit levhanın enerji absorpsiyonunun artacağı sonucuna varmışlardır. Kauçuk ve alüminyum tabakanın arayüzey bağlanmasının yüksek olmasına rağmen ön yüzde kauçuk bulunan tabakalı kompozit daha iyi performansa sahiptir. Ancak arayüzey bağlanmasının zayıf olması durumunda arka yüz konfigürasyonunda daha yüksek enerji absorpsiyonuna yol açtığı görülmektedir (Khodadadi vd., 2020).
Karl ve arkadaşları, dinamik mekanik analiz ve zamansıcaklık süperpozisyon ilkesinden yararlanarak küçük kalibrelere karşı balistik koruma için ideal bir malzeme geliştirmişlerdir. Bu malzemeyi balistik deneylerle analiz etmişler ve camsı geçiş sıcaklığı, sertlik ve sönüm açısından diğer ideal olmayan kauçuklarla karşılaştırmışlardır. Belirli camsı geçiş sıcaklığı ve sertliğe sahip bir malzemeyi doğru seçerek çelik-kauçukalüminyum zırhın balistik özelliklerinin geliştirilebileceğini göstermişlerdir. 50 ShA sertliğe sahip seçilen malzeme (bütil kauçuk), balistik çarpma sırasında enerji emilimini yaklaşık \%8 oranında arttırmıştır. Bu sonuç, optimize edilmemiş özelliklere sahip diğer kauçuktan 2 kat daha iyi olduğu gösterilmiştir (Karl $\mathrm{vd}, 2020)$.

Sunulan bu çalışmada kompozit plakalar ile balistik özellikleri artırılmış alüminyum plaka çekirdekli sandwich levhanın balistik performansları, NIJ 0108.01 standardında belirtilen test değişkenleri ve performans gerekliliklerine göre LS DYNA ${ }^{\circledR}$ yazılımı ile nümerik olarak incelenmiştir.

\section{Materyal ve Metot}

\section{1. Çok Katmanlı Plaka Tasarımı}

Şekil 1'de görüldüğü gibi malzeme 3 katmandan oluşmaktadır. Alt ve üst tabakalar karbon-aramid/epoksi kompozitlerden oluşurken orta katman Al5083-H116 alüminyum alaşımı levhadan oluşmaktadır. Karbon-aramid/epoksi kompozitin modellenmesi için MAT_COMPOSITE_FAILURE_SOLID_MODEL (MAT 59) malzeme kartı kullañılmıştır. Ā $5083-\mathrm{H} 116$ alüminyum alaşımı için ise MAT 15 Johnson Cook malzeme modeli tercih edilmiştir. Johnson-Cook tarafından tanımlanan malzeme modeli ve Johnson-Cook hasar modeli eşitlikleri Denklem (2.1 ve 2.2)'de verilmiştir.

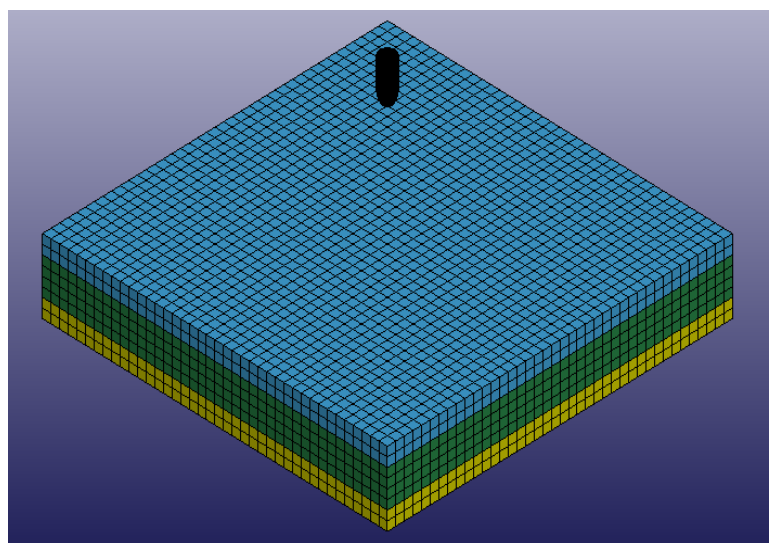

Şekil 1. Katmanlı kompozit ve $9 * 19 \mathrm{~mm}$ parabellum mermi çekirdeği

$\sigma=\left[A+B \varepsilon^{n}\right] *\left[1+C \ln \left(\frac{\dot{\varepsilon}}{\dot{\varepsilon}_{0}}\right)\right] *\left[1-\left(\frac{T-T_{0}}{T_{m}-T_{0}}\right)^{m}\right]$

$\varepsilon_{f}=\left[D_{1}+D_{2} \exp \left(D_{3}\left(\frac{\sigma_{m}}{\sigma_{e q}}\right)\right)\right]\left[1+D_{4} \frac{\dot{\varepsilon}_{P}}{\dot{\varepsilon}_{0}}\right]\left[1+D_{5} \frac{T-T_{0}}{T_{m}-T_{0}}\right]$ 
Denklem (2.1)'de görülen A akma gerilmesi, B pekleşme modülü, $\mathbf{C}$ birim şekil değiştirme hızı sabiti, n pekleşme üstel katsayısı, m termal yumuşama üstel katsayısı olup malzemeye göre değişmektedir. Birçok farklı deneyin sonucunda belirtilen malzeme sabitleri ve değerleri tespit edilirler. Johnson-Cook malzeme modeli ampirik bir ifade olup malzemede oluşması beklenen gerilmeyi; akma gerilmesi, birim şekil değiştirme hızı $(\dot{\varepsilon})$ ve sicaklığa bağlı $(\mathrm{T})$ olarak ifade etmektedir. Denklemdeki ilk parantez içerisindeki ifade şekil değiştirme pekleşmesini, ikinci parantez içerisindeki ifade ise birim şekil değiştirme hızına bağlı pekleşmeyi ve son parantez ise sıcaklık değişiminin malzeme davranışı üzerindeki etkisini tanımlamaktadır (Deniz vd., 2010). Bu çalışmada kullanılan Al5083 H116 Alümiyum malzeme için gerekli malzeme sabitleri Tablo 1'de görülmekte olup literatürden temin edilmiştir (Rashed ve diğerleri, 2015).

Johnson-Cook hasar modeli de Denklem (2.2)'de görülmektedir. $D_{1-5}$ hasar modeli sabitleridir. Kırılma gerinimi denkleminde $\sigma_{m}$ ortalama gerilme, $\sigma_{e q}$ ise eşdeğer gerilmeyi ifade eder. Hasar modeli denkleminin ilk kısmı, gerinimi gerilme üç eksenlilik oranının bir fonksiyonu olarak ifade ederken ikinci kısmı gerinim hızı etkilerini ve son kısım da sıcaklık etkilerini ifade eder (Deniz vd., 2002).

Tablo 1. Al5083 H116 Alüminyum malzeme için LS DYNA ${ }^{\circledR}$, MAT 15 Johnson-Cook model parametreleri (Rashed ve diğerleri, 2015).

\begin{tabular}{|c|c|c|}
\hline Parametre & Sembol ve Birim & Değer \\
\hline Yoğunluk & $R O\left(\mathrm{~kg} / \mathrm{m}^{3}\right)$ & 2700 \\
\hline Kayma Modülü & $G(P a)$ & $2.69 \mathrm{E} 10$ \\
\hline Elastisite Modülü & $E(P a)$ & 70 E9 \\
\hline Poisson Oranı & $P R$ & 0.3 \\
\hline Akma Gerilmesi & $A(P a)$ & $1.67 \mathrm{E} 8$ \\
\hline Pekleşme Modülü & $B(P a)$ & $5.96 \mathrm{E} 8$ \\
\hline Birim Şekil & & \\
\hline Değiştirme $\mathrm{H} ı z \imath$ & $C$ & 0.001 \\
\hline Sabiti & & \\
\hline $\begin{array}{l}\text { Termal Yumuşatma } \\
\text { Üssü }\end{array}$ & $m$ & 0.859 \\
\hline Pekleşme Üssü & $n$ & 0.551 \\
\hline Erime Slcaklı̆̆ & $T M(K)$ & 893 \\
\hline Oda Sıcaklı̆̆ & $T R(K)$ & 300 \\
\hline $\begin{array}{l}\text { Referans Gerinim } \\
\text { Oranı }\end{array}$ & $\operatorname{EPSO}\left(s^{-1}\right)$ & 1 \\
\hline 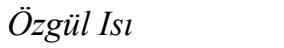 & $C P\left(\mathrm{Jg}^{-1} \mathrm{~K}^{-1}\right)$ & 910 \\
\hline Kesme Basinc & $P C(P a)$ & -1.5 E9 \\
\hline Hasar Parametresi & $D_{1}$ & 0.0261 \\
\hline Hasar Parametresi & $D_{2}$ & 0.263 \\
\hline Hasar Parametresi & $D_{3}$ & -0.349 \\
\hline Hasar Parametresi & $D_{4}$ & 0.247 \\
\hline Hasar Parametresi & $D_{5}$ & 16.8 \\
\hline Hasar Esnasındaki & & \\
\hline $\begin{array}{l}\text { Max Efektif } \\
\text { gerinim }\end{array}$ & EFFEPS & 2 \\
\hline
\end{tabular}

Tablo 1'de görülen parametrelerin yanında bu malzeme modelinin kullanılabilmesi için hal denklemine (EOS) ihtiyaç vardır. Bu nedenle EOS LINEAR POLYNOMIAL kartında Bulk Modülü değeri $\left(C_{1}\right)^{-} 5.83 * 1 \overline{0}^{10}$ girilerek hal denklemi tanımlanmış olur.
Alt ve üst katmandaki karbon-aramid/epoksi kompozitin modellenmesi için kullanılan MAT 59 malzeme kartı, kalın ortotropik kompozit yapıların darbe ve ezilme davranışlarının analizinde kullanılır. Bu model, katı elemanlarla çalışır. Bu model için hasar kriterleri denklem (2.3) ila denklem (2.10) arasındaki ifadeler ile verilmiştir (Korkut, 2017) (LSTC, 2007) (Park vd., 2012).

Fiber çekme $\left(\sigma_{11}>0\right)$ :

$\frac{\sigma_{11}^{2}}{X_{T}^{2}}+\frac{\tau_{12}^{2}}{S_{12}^{2}}+\frac{\tau_{31}^{2}}{S_{31}^{2}}<1$

Matris çekme (fiber çekme ile beraber) $\left(\sigma_{22}>0\right)$ :

$\frac{\sigma_{22}^{2}}{Y_{T}^{2}}+\frac{\tau_{12}^{2}}{S_{12}^{2}}+\frac{\tau_{23}^{2}}{S_{23}^{2}}<1$

Kalınlık doğrultusunda kayma $\left(\sigma_{11}>0\right)$ :

$\frac{\sigma_{11}^{2}}{X_{T}^{2}}+\frac{\tau_{31}^{2}}{S_{31}^{2}}<1$

Kalınlık doğrultusunda çekme (delaminasyon) $\left(\sigma_{33}>0\right)$ :

$\frac{\sigma_{33}^{2}}{z_{T}^{2}}+\frac{\tau_{23}^{2}}{S_{23}^{2}}+\frac{\tau_{31}^{2}}{S_{31}^{2}}<1$

Kalınlık doğrultusunda kayma (matris çekme ile beraber) $\left(\sigma_{22}>0\right)$

$\frac{\sigma_{22}^{2}}{Y_{T}^{2}}+\frac{\tau_{23}^{2}}{S_{23}^{2}}<1$

Fiber $\operatorname{basma}\left(\sigma_{11}<0\right)$ :

$\frac{\sigma_{11}^{2}}{X_{C}^{2}}<1$

Matris basma $\left(\sigma_{22}<0\right)$ :

$\frac{\sigma_{22}^{2}}{\left(S_{11}+S_{23}\right)^{2}}+\frac{\sigma_{22}}{Y_{C}}\left[\left(\frac{Y_{C}^{2}}{\left(S_{12}+S_{23}\right)}\right)^{2}-1\right]+\frac{\tau_{12}^{2}}{S_{12}^{2}}+\frac{\tau_{31}^{2}}{S_{31}^{2}}<1$

Kalınlık doğrultusunda basma $\left(\sigma_{33}<0\right)$ :

$\frac{\sigma_{33}^{2}}{\left(S_{31}+S_{23}\right)^{2}}+\frac{\sigma_{33}}{Z_{C}}\left[\left(\frac{Z_{C}^{2}}{\left(S_{31}+S_{23}\right)}\right)^{2}-1\right]+\frac{\tau_{31}^{2}}{S_{12}^{2}}+\frac{\tau_{23}^{2}}{S_{23}^{2}}<1$ 
Tablo 2. Karbon-aramid/epoksi kompozit malzeme tanımı için kullanılan değerler (Berk vd., 2017).

\begin{tabular}{cc} 
& Karbon-Aramid/Epoksi \\
\hline$\rho\left(\mathrm{kg} / \mathrm{m}^{3}\right)$ & 1148 \\
$E_{1}(\mathrm{MPa})$ & 47700 \\
$E_{2}(\mathrm{MPa})$ & 47700 \\
$E_{3}(\mathrm{Mpa})$ & 28620 \\
$X_{t}(\mathrm{Mpa})$ & 552 \\
$X_{c}(\mathrm{Mpa})$ & 273 \\
$Y_{t}(\mathrm{MPa})$ & 552 \\
$Y_{c}(\mathrm{MPa})$ & 273 \\
$Z_{t}(\mathrm{MPa})$ & 331 \\
$Z_{c}(\mathrm{MPa})$ & 164 \\
$G_{12}(\mathrm{MPa})$ & 2345 \\
$G_{23}(\mathrm{MPa})$ & 1407 \\
$G_{32}(\mathrm{MPa})$ & 1407 \\
$S_{12}(\mathrm{MPa})$ & 82 \\
$S_{23}(\mathrm{MPa})$ & 49 \\
$S_{31}(\mathrm{MPa})$ & 49 \\
$v_{12}$ & 0.1 \\
$v_{23}$ & 0.06 \\
$v_{31}$ & 0.06 \\
\hline
\end{tabular}

Çekme/basma gerinimi ya da maksimum efektif gerinimi kullanıcı tarafından belirlenen sınırı geçen elemanlar tamamen hasara uğramış sayılmış ve analizden silinmiştir.
Tablo 2'de MAT 59 malzeme kartında kullanılan malzeme parametreleri görülmektedir. LS DYNA ${ }^{\circledR}$ yazılımında Lagrange yaklaşımı için hasara uğrayan elemanlar için erozyon kartı tanımlanması gerekmektedir. $\mathrm{Bu}$ nedenle MAT 00 (MAT_ADD_EROSION) kartı oluşturulmuştur. $\varepsilon_{m x p}=0.014$, $\varepsilon_{m n p}=-0.005, \varepsilon_{s h}=0.095$ olacak şekilde literatürden bulunan değerler doğrultusunda tanımlama yapılmıştır (Berk vd., 2017).

Merminin herhangi bir deformasyona uğramayıp malzeme üzerinde meydana getirdiği hasarı gözlemlemek adına mermi çekirdeği malzemesi için MAT 20 (MAT_RIGID) malzeme modeli kullanılmış ve çelik malzeme tanımı yapılmıştır. MAT 20 kartında kullanılan malzeme özellikleri Tablo 3'de verilmiştir.

Tablo 3. MAT 20 Çelik malzeme özellikleri.

\begin{tabular}{ccc}
\hline Yoğunluk $\left(\mathrm{kg} / \mathrm{m}^{3}\right)$ & $\begin{array}{c}\text { Elastisite Modülü } \\
(\mathrm{Pa})\end{array}$ & Poisson Oranı \\
\hline 7850 & $2.1 \mathrm{E} 11$ & 0.3 \\
\hline
\end{tabular}

\subsection{Sayısal Analiz Modeli}

\subsubsection{Aerodinamik Analiz Modeli}

Namlu ucundan çıkan mermi hızlarının numune ön yüzünde hangi değerde alınacağ 1 hava direnci dikkate alınarak gerçekleştirilen CFD analizleri ile bulunmuştur. NIJ 01108.1

Tablo 4. NIJ 0108.01 standardında belirtilen koruma seviyeleri ve mermi hızlarl (National Institute of Justice,1985)

\begin{tabular}{ccccccc}
\hline $\begin{array}{c}\text { Koruma } \\
\text { Seviyesi }\end{array}$ & $\begin{array}{c}\text { Test } \\
\text { Mühimmatı }\end{array}$ & $\begin{array}{c}\text { Nominal } \\
\text { Mermi } \\
\text { Cekirdek } \\
\text { Kütlesi }\end{array}$ & $\begin{array}{c}\text { Onerilen } \\
\text { Namlu }\end{array}$ & $\begin{array}{c}\text { Gerekli } \\
\text { Mermi } \\
\text { Hızı } \\
(\mathrm{m} / \mathrm{s})\end{array}$ & $\begin{array}{c}\text { Numune } \\
\text { Başına } \\
\text { Gerekli } \\
\text { Vuruş }\end{array}$ & $\begin{array}{c}\text { Izin Verilen } \\
\text { Penetrasyon }\end{array}$ \\
\hline II-A & $9 \mathrm{~mm}$ & $8 \mathrm{gr}$ & $10-12 \mathrm{~cm}$ & $\begin{array}{l}332 \\
\pm 12\end{array}$ & 5 & 0 \\
II & $9 \mathrm{~mm}$ & $8 \mathrm{gr}$ & $10-12 \mathrm{~cm}$ & $\begin{array}{l}358 \\
\pm 12\end{array}$ & 5 & 0 \\
III-A & $9 \mathrm{~mm}$ & $8 \mathrm{gr}$ & $24-26 \mathrm{~cm}$ & $\begin{array}{l}426 \\
\pm 15\end{array}$ & 5 & 0 \\
\hline
\end{tabular}

Malzemenin balistik seviyesini belirleme adına National Institute of Justice (NIJ) tarafindan balistik koruyucu malzemeler için yayımlanan NIJ Standard 0108.01'de 9x19 mm 8 gram çekirdek ağırlığındaki Parabellum FMJ mermi için farklı seviyelerde belirlenen mermi hızlarında analizler gerçekleştirilmiştir. Test standardında verilen $5 \mathrm{~m}$ atış mesafesi boyunca hava tarafindan mermi üzerine aerodinamik direnç kuvveti etkiyecektir.

Merminin başlangıçta sahip olduğu kinetik enerji ve hedefe vardığı andaki kinetik enerji cinsinden, enerji dengesi:

$$
\frac{1}{2} m V_{1}^{2}=\frac{1}{2} m V_{2}^{2}+F_{D} x
$$

şeklinde basitçe ifade edilebilir. Eşitliğin sağ tarafındaki ifade, hava direnç kuvveti tarafından yapılan işi göstermektedir. Hava direnç kuvveti (sürükleme kuvveti) ise denklem 2.12' de verilmiştir.

$$
F_{D}=\frac{1}{2} \rho A V^{2} C_{D}
$$

$\mathrm{Bu}$ ifadede $\rho$ : hava yoğunluğunu, A: hava içerisindeki cismin akış doğrultusuna olan dik kesit alanı, V: cisim ve hava arasındaki bağıl hızı temsil eder. $C_{D}$ ise aerodinamik direnç katsayısıdır ve cismin geometrisi, havanın basınç, sıcaklık ve yoğunluk gibi özellikleri ile değişir.

Merminin çarpma hızını tayin edebilmek için direnç kuvvetine ve dolayısıyla direnç katsayısına ihtiyaç vardır. $\mathrm{Bu}$ nedenle iki boyutlu basitleştirilmiş bir CFD analizi yapılmıştır. Dış balistiğin karmaşık çalışma konuları düşünüldüğünde burada basit bir yaklaşım izlenip mermi hızı tayin edilmiştir. Mach sayısına göre değişen direnç katsayısı değerleri incelendiğinde literatürdeki çalışmalar ile uyumlu sonuçlar verdiği gözlemlenmiştir. 


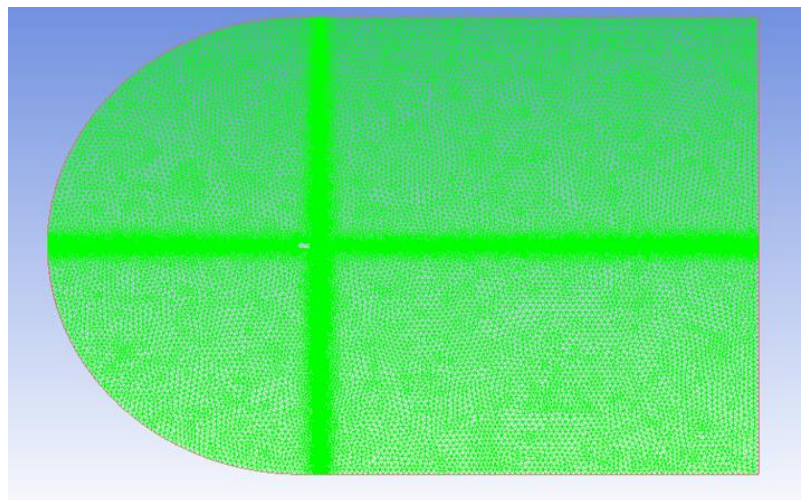

Şekil 2. 2D CFD modeli

Şekil 2'de görüldüğü gibi hava akış hacmi, mermi boyutuna oranla oldukça büyük modellenmiştir. Bunun nedeni, mermi hareketi esnasında meydana gelen akış bölgelerini ve mermi etkisini daha doğru bir şekilde gözlemlemektir. Yine bu sebeplerden dolayı mermiye yakın olan bölgelerde mesh yapısı görüldüğü üzere sıklaştırılmıştır. Toplam $4.2 \quad 10^{6}$ elemandan oluşan bir ağ yapısı kullanılmıştır. Kullanılan eleman sayısının optimum değerlere uygun olduğu literatürden görülmüştür (Selimli, 2020).

Bu sıkıştırılabilir dış akış problemi için çözücü tipi olarak basınç temelli çözücü kullanılmıştır. Basınç hız ilişkilendirme algoritması olarak da Coupled (birleşik) tercih edilmiştir. $\mathrm{Bu}$ sayede üstün performanslı ve hizlı bir çözüm elde edilebilmektedir. Pseudo Transient opsiyonunun aktif hale getirilmesi ile başlangıçta sürekli rejim problemi olarak seçilen modelde anlık değişimler fotoğraflanarak geçici rejim gibi sonuçlar görüntülenmektedir.

Türbülans etkilerini modellemek için Spalart Allmaras türbülans modeli kullanılmıştır (Selimli, 2020). Bu model, havacılık ve uzay uygulamalarında sıkıştırılabilir dış akış problemlerinde sıklıkla tercih edilmektedir. Tek denklemli model olarak da bilinen Spalart Allmaras, kinematik Eddy viskozitesini modelleyen bir transport denklemini çözmektedir.

Sıkıştırılabilir akış üzerinde çalışıldığı için yoğunluk değiş̧ken olmaktadır. Bu nedenle yoğunluk, ideal gaz denklemi ile hesaplanacaktır. $\mathrm{Bu}$ denklem ile yoğunluk hesabının yapılabilmesi için sıcaklık değerlerine ihtiyaç vardır. Bu nedenle enerji denklemi de aktif hale getirilerek sıcaklık değerleri hesaplanır. Bununla birlikte havanın viskozitesi de sabit kabul edilemez. Bilindiği üzere gaz ve sıvıların viskozitesi, sıcaklık ve basınç etkisi ile değişmektedir. Basıncın viskozite üzerindeki etkileri ihmal edilebilirken sıcaklığın etkisi önemlidir ve göz ardı edilemez. Sıvıların viskozitesi artan sıcaklık ile azalırken gazların viskozitesi artmaktadır. Akışkanın viskozitesi de meydana getirdiği direnç kuvveti ve katsayısı için önem arz eder. $\mathrm{Bu}$ çalışmada viskozitenin hesaplanması için Denklem 2.13'te verilen Sutherland Kanunu'ndan yararlanılmıştır (Raoelison vd., 2021). Bu kanun, belli bir referans sıcaklık değeri için bilinen viskozite değerinden yararlanarak herhangi bir sıcaklık değerinde viskozitenin hesaplanmasını sağlamaktadır.

$\mu=\mu_{0} .\left(\mathrm{T} / \mathrm{T}_{0}\right)^{3 / 2} .\left(\mathrm{T}_{0}+\mathrm{S}\right) /(\mathrm{T}+\mathrm{S})$

Burada; $\mu$ istenen sicaklıktaki viskozite (Pas), $\mu_{0}$ ise $\mathrm{T}_{0}(273$ K) mutlak sicaklığındaki bilinen viskozite değeri (Pas), $\mathrm{T}$ viskozitesi bulunmak istenen sicaklık (K), S gaz cinsine bağlı olup hava için $\mathrm{S}=110 \mathrm{~K}$ alınabilir.
Akış alanı Pressure-Far-Field olarak tanımlanarak sınır şartları girilmiştir. NIJ 0108.01 standardında koruma seviyelerinde verilen mermi hızlarının maksimum değerleri göz önüne alınarak analizlerde kullanılacak Mach sayıları sırası ile; 1.00233, 1.07809, 1.28497 şeklindedir.

\subsubsection{Balistik Koruyucu Plakanın Sonlu Elemanlar Modeli}

Şekil 1'de görülen 3 katmandan oluşan tabakalı kompozit yapının en ve yüksekliği birbirine eşit ve 200 mm'dir. Karbonaramid/epoksi kompozit malzemeden meydana gelen alt ve üst kısımdaki katmanların kalınlıkları $10 \mathrm{~mm}$ iken orta kısımda bulunan Alüminyum katmanın kalınlığ $20 \mathrm{~mm}$ 'dir. Hibrit kompozit yapı, katı elemanlar ile modellenmiş ve 12.800 adet eleman kullanılmıştır. 9x19 mm Parabellum mühimmat ölçüleri (Şekil 3) kullanılarak tasarlanan mermi çekirdeği, 8335 adet kabuk eleman kullanılarak modellenmiştir.

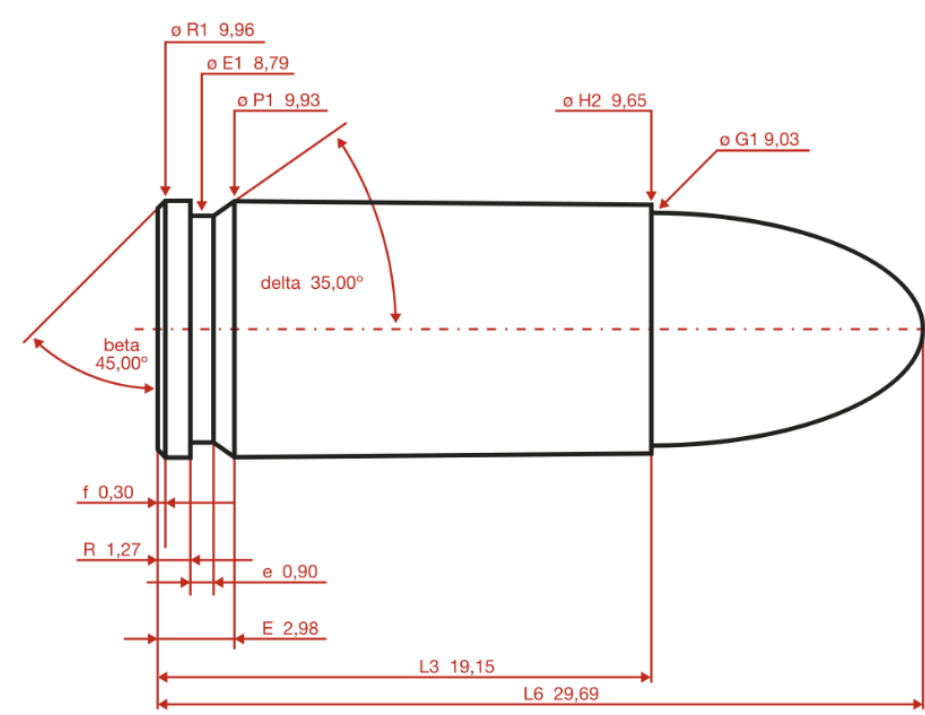

Şekil 3. NIJ 9x19 mm Parabellum mühimmat ölçüleri (URL, 2021)

Rijit yapışma bağlantısını temsilen TIED_NODES_TO_SURFACE contact kartı tanımlanmıştır. Böylelikle orta tabakanın alt ve üst yüzeyindeki düğ̈̈m noktaları, plakaların temas yüzeyleri ile bağlanmıştır. Mermi çekirdeği ve her bir kompozit katman arasında ilişkilendirme amacı ile AUTOMATIC_ONE_WAY_SURFACE_TO_SURFACE kontak tanımlanmıştır.

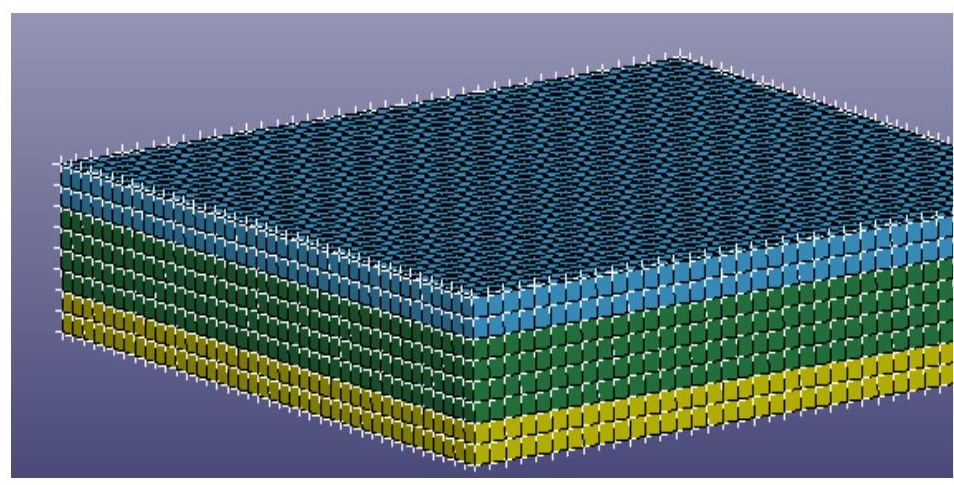

Şekil 4. Katmanlı kompozit yapının sabitlenmesi. 
Katmanlı kompozit Şekil 4'de görüldüğü gibi yan yüzeylerindeki düğüm noktalarından her yöndeki dönme ve öteleme serbestliği sinırlandırılarak sabitlenmiştir.
INITIAL_VELOCITY_GENERATION kartı kullanılarak mermi hızları tanımlanmıştır.

\section{Araştırma Sonuçları ve Tartışma}

\subsection{Aerodinamik Analiz Sonuçları}

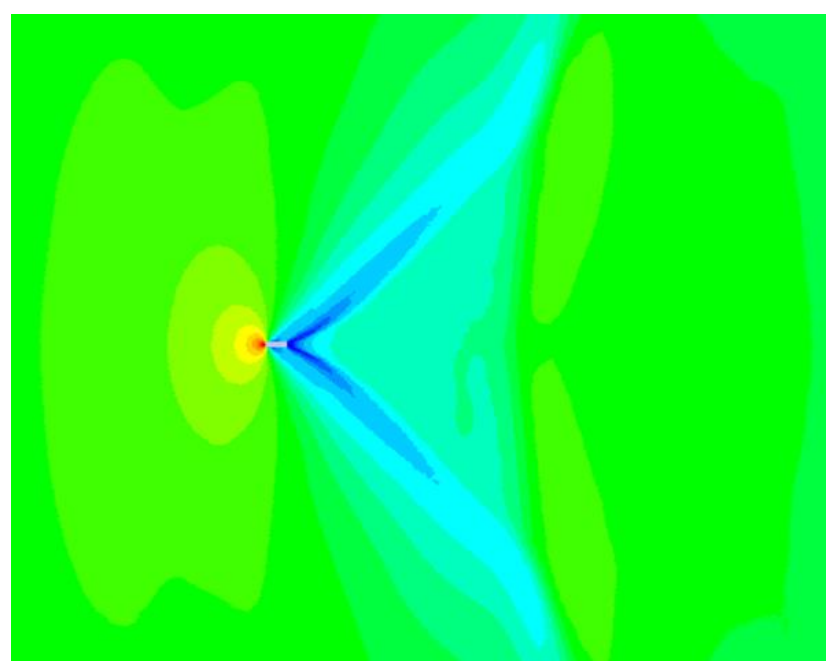

(a)

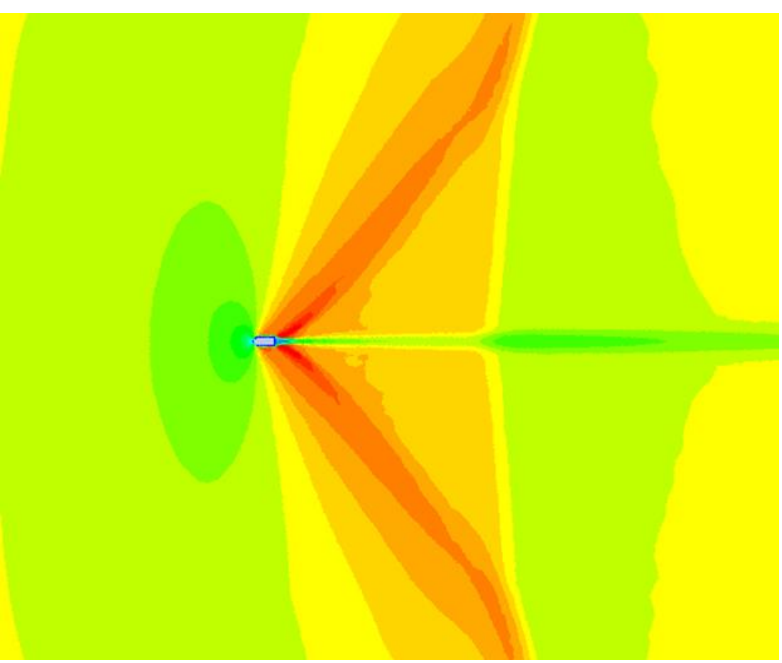

(b)

Şekil 5. Mach=1.00233 için kontür görüntüleri a)Basınç dă̆ılımı b)Hız dă̆ılımı.

Şekil 5. a'da açıkça görüldüğü gibi en yüksek basınç değeri merminin ucunda meydana gelir. Bu nedenle merminin formu oldukça önemli ve $C_{D}$ (Sürükleme katsayısı) katsayısında etkilidir. Şekil 5. b'de hız dağılımı gözlemlenmektedir. Mermi duvarlarında kaymama şartı nedeniyle hız 0 (sıfır) olarak görünmektedir. Her 2 şekil incelendiğinde durgunluk bölgesi, akış ayrılmaları, alçak ve yüksek basınç bölgeleri gibi akış bölgeleri gözlemlenebilmektedir. Hesaplanan $C_{D}$ değerleri sayesinde Denklem (2.12) kullanılarak etki eden direnç kuvvetleri, (2.11) kullanılarak da mermi son hızları bulunmuştur. Bulunan bu hız değerleri Tablo 5'de verilmiştir. Merminin akış doğrultusuna dik kesit alanı küçük olduğundan direnç kuvveti değerleri de düşük çıkmaktadır. Bu nedenle havanın mermi hızı üzerinde çok önemli bir değişiklik yapmadığı sonucu çıkarılmıştır. Böylelikle LSDYNA $^{\circledR}$ yazılımı ile yapılacak olan yüksek hızlı darbe analizlerinde bu etki dikkate alınmadan hız değerleri de kullanılabilecektir.

Tablo 5. Farkl koruma seviyeleri için hesaplanan son hız değerleri

\begin{tabular}{cccc}
\hline & II-A & II & III-A \\
\hline$V_{i l k}(\mathrm{~m} / \mathrm{s})$ & 344 & 370 & 441 \\
$C_{D}$ & 0.223 & 0.211 & 0.2797 \\
$F_{D}(N)$ & 0.9877 & 1.0812 & 2.036 \\
$V_{\text {son }}(\mathrm{m} / \mathrm{s})$ & 342.2 & 368.17 & 438.11 \\
\hline
\end{tabular}

\subsection{Balistik Koruyucu Plakanın Sonlu Elemanlar Analiz Sonuçları}

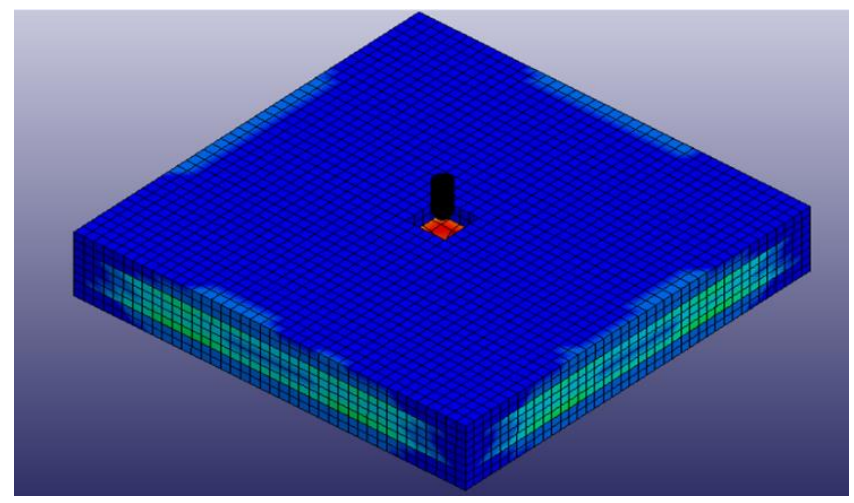

Şekil 6. II-A koruma seviyesi için katmanlı kompozitte meydana gelen hasar.

Şekil 6'da görülmüş olduğu gibi NIJ 0108.01 standardında IIA koruma seviyesi için belirtilen $344 \mathrm{~m} / \mathrm{s}^{\prime}$ lik mermi hızında, üst katmanda bulunan karbon-aramid/epoksi kompozit için malzeme kartında tanımlanan parametre değerleri aşıldığından mermi ve kompozitin temas ettiği bölgede limit hasar değerlerini aşan elemanlar otomatik olarak kaldırılarak fiziksel penetrasyon gösterilmiştir. Ortada bulunan alüminyum çekirdekte çöküntü meydana gelmiş fakat kurşun bu tabakada delinmeye sebep olmamıştır. Şekil 7'de merminin kinetik enerjisinin tamamen absorbe edilişi net olarak gözükmektedir. 


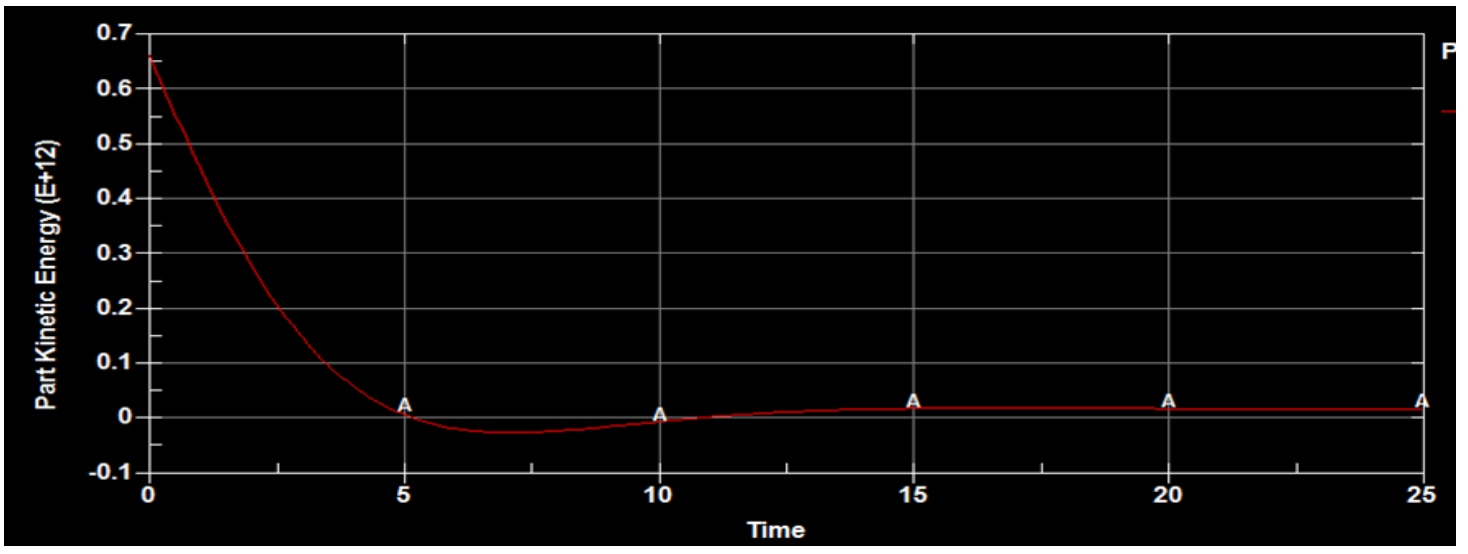

Şekil 7. Mermi çekirdeğinin kinetik enerjisinde zamanla meydana gelen değişim(II-A).

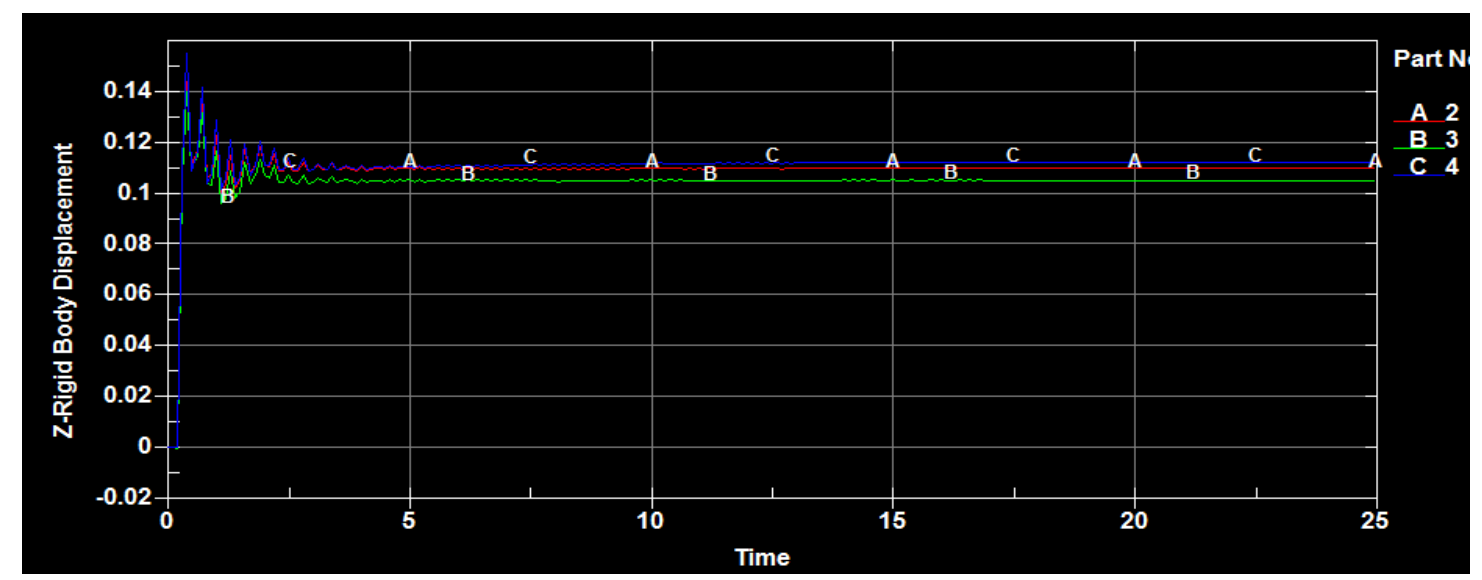

Şekil 8. Kompozit tabakalarda z- yönünde meydana gelen yer değiştirme- zaman grafiği (II-A).

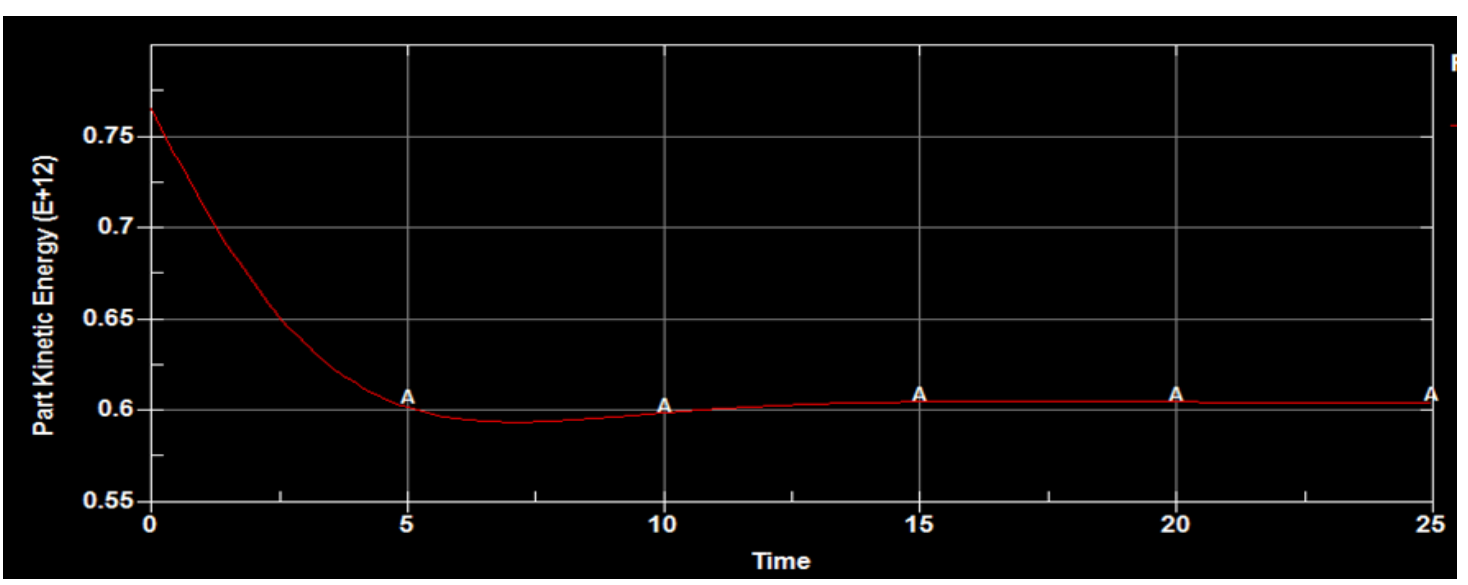

Şekil 9.Mermi çekirdeğinin kinetik enerjisinde zamanla meydana gelen değişim (II). 


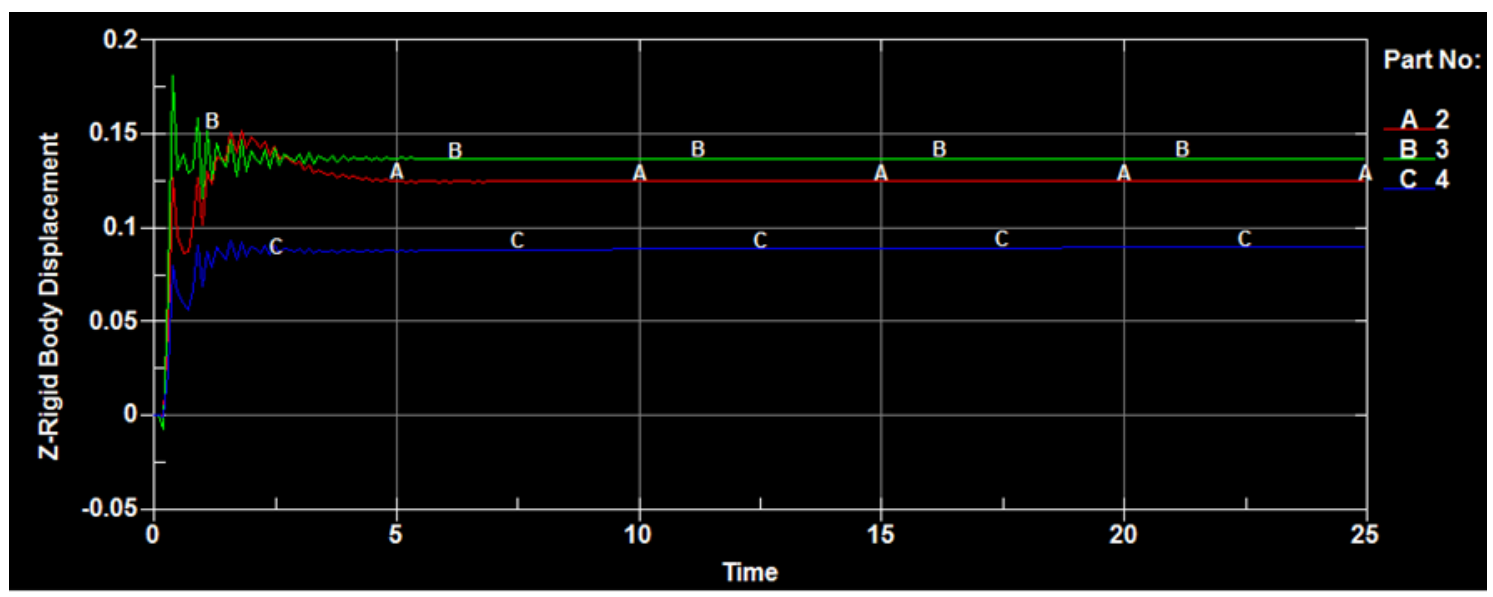

Şekil 10. Kompozit tabakalarda z-yönünde meydana gelen yer değiştirme- zaman grafiği (II).

Şekil 8 ve Şekil 10'da verilen deplasman-zaman grafiklerinde; A: en üst kısımda bulunan karbon-aramid/epoksi kompozit tabakayı, B:orta kısımda bulunan alüminyum alaşımlı katmanı, C: alt kısımda bulunan karbon-aramid/epoksi kompozit tabakayı göstermektedir. Yüksek hılı darbe esnasında üst katmandaki kompozit tabakaya gelen darbe enerjisi ve gerilim, tabakanın mermi ile etkileşimi esnasında tabaka içine yayılamamıştır. Fakat diğer katmanlarda gerilme dalgalarının malzeme içerisinde yayılması için yeterli zaman bulunmuştur.
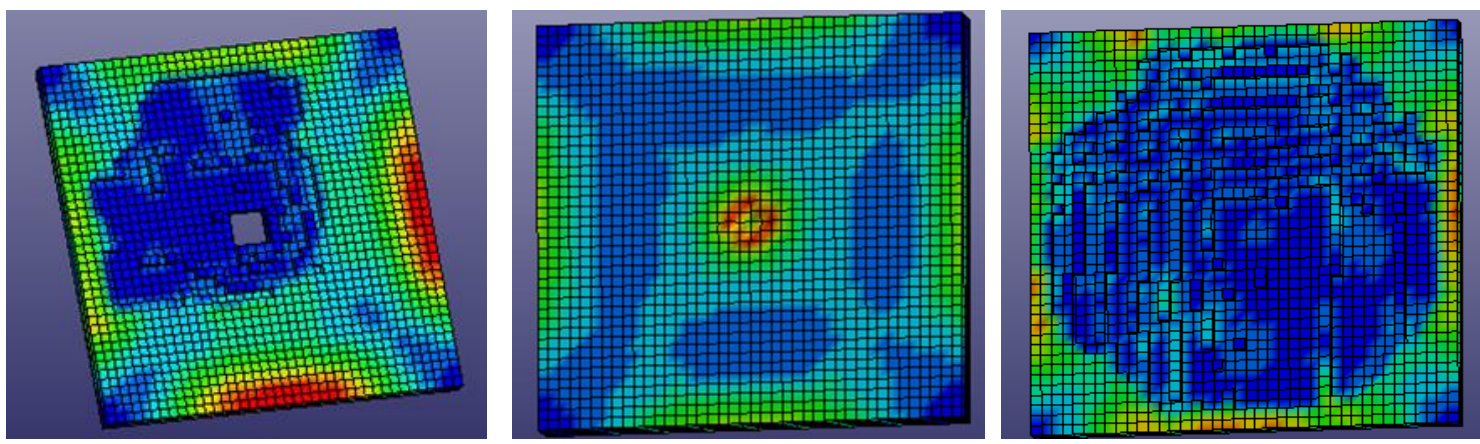

Şekil 11. Koruma seviyesi II için katmanlarda meydana gelen hasarlar.

$370 \mathrm{~m} / \mathrm{s}$ mermi hızı için katmanlı kompozit yapının gösterdiği davranış Şekil 11'de verilmiştir. Orta katmanda yine herhangi bir delinme görülmemiştir. Fakat 3. katmana aktarılan darbe enerjisi sebebi ile şekil değiştirme limitlerini aşan elemanlar silinmiştir.

Sonuçlar incelendiğinde mermi enerjisinin tasarlanan zırh malzemesi tarafından soğurulamadığg Şekil 7 ve Şekil 9'da gözlemlenmiştir. Orta katmanda bulunan Alüminyum malzeme, mermi yönünü saptırmaya yönelik bir davranış göstermektedir. Merminin artık enerjisinin çok düşük seviyelere inmesi nedeniyle önerilen tasarım, hafif ve ekonomik balistik koruyucu alternatif bir malzeme olacaktır.

\section{Sonuç}

Bu çalışmada öncelikli olarak CFD analizleri ile NIJ 018.01 standardında 9x19 mm parabellum merminin tabancadan çıkış hızı ile havada hareketi sonrası belirlenen $5 \mathrm{~m}$ atış mesafesi sonrasındaki hedef plakaya çarpma hızı belirlenmiştir. Böylece hava direnci göz önüne alınan analizler yapılmıştır. Belirlenen standarda uygun balistik performansı iyileştirilmiş, ön ve arka kısmında katmanlı kompozit plaka ve orta kısmında alüminyum plaka olan bir sandviç yapı tasarımı gerçekleştirilmiştir. Bu malzeme tasarımında ön katmanlı kompozit katmanın, merminin kinetik enerjisinin önemli bir kısmını hasara uğratarak alması ve orta katmandaki yüksek şekil değiştirme kabiliyetine sahip alüminyum plakada sürtünme ve plastik şekil değiştirme ile mermi enerjisinin çok büyük oranda absorbe edilerek sönümlenmesi hedeflenmiştir. Mermi üzerindeki şekil değiştirmeler göz ardı edilerek maksimum hasar oluşturacak bir durum, mermi için çelik malzeme tanımı gerçekleştirilerek elde edilmek hedeflenmiştir. Arka kompozit katmanlı plaka ise alüminyum orta katmanın deformasyon sırasında oluşturacağı lokal hasarları önlemek ve alüminyumu delerek geçmesi durumunda kurşunu durdurması için kullanılmıştır. Tasarlanan alüminyum çekirdekli katmanlı kompozit sandviç yapının balistik performansı, sonlu elemanlar analizleri ile incelenmiştir. Belirlenen katman sayıları ve kompozit konfigürasyonlarına göre tasarlanan plakalara yapılan analiz sonuçlarında, 344 ve $370 \mathrm{~m} / \mathrm{s}$ hızlardaki 9x19mm parabellum mermilerin enerjisinin kompozit plaka tarafindan soğurulduğu yani mermilerin plakalarda delinmeye yol açmadığı görülmüştür. 


\section{Kaynakça}

Berk, B., Karakuzu, R., \& Toksoy, A. K. (2017). An experimental and numerical investigation on ballistic performance of advanced composites. Journal of Composite Materials, 51(25), 3467-3480.

https://doi.org/10.1177/0021998317691810

Bitlisli, B., \& Yazıcı, M. (2019). Araç Zırhlamada Kullanılan Kompozit Malzemelerin Balistik Performanslarının Incelenmesi. Uludağ University Journal of The Faculty of Engineering, 24(1), 25-34. https://doi.org/10.17482/uumfd.494262

Deniz, T., Namık, K., \& R.Orhan, Y. (2010). Balistik penetrasyon benzetimlerinde johnson-cook malzeme modeli sabitlerinin etkisinin incelenmesi. SAVTEK 2010 Savunma Teknolojileri Kongresi, 1-10.

Karl, J., Kirsch, F., Faderl, N., Perko, L., \& Fras, T. (2020). Optimizing viscoelastic properties of rubber compounds for ballistic applications. Applied Sciences (Switzerland), 10(21), 1-15. https://doi.org/10.3390/app10217840

Kasım, H. (2021). Investigation on the ballistic performance of rubber-aluminum (AA7075-T651) laminated plates reinforced with borosilicate glass balls. Proceedings of the insiltution of mechanical engineers part l-Journal of Materials-Design and Applicatıons, 1464420721, 3-29. https://doi.org/10.1177/14644207211044460

Khodadadi, A., Liaghat, G., Shahgholian-Ghahfarokhi, D., Chizari, M., \& Wang, B. (2020). Numerical and experimental investigation of impact on bilayer aluminumrubber composite plate. Thin-Walled Structures, 149(January), 106673. https://doi.org/10.1016/j.tws.2020.106673

LSTC. (2007). LS-DYNA® Keyword User's Manual Version 971.

National Institute of Justice. (1985). In Ballistic Resistance Protective Materials 0108.01.

Oliveira, M. S., Luz, F. S. da, Lopera, H. A. C., Nascimento, L. F. C., Garcia Filho, F. da C., \& Monteiro, S. N. (2021). Energy absorption and limit velocity of epoxy composites incorporated with fique fabric as ballistic armor - a brief report. Polymers, 13(16).

https://doi.org/10.3390/polym13162727

Ouellet, S., Levine, J., \& Dionne, J. P. (2008). Parametric study on rigid plates, compressible foams and air gaps combinations for mitigating blast in personal protection applications. Proceedings of Personal Armour System Symposium, 131-139.

Park, C.-K., Kan, C.-D. (Steve), Hollowell, W. T., \& Hill, S. I. (2012). Investigation of Opportunities for Lightweight Vehicles Using Advanced Plastics and Composites. Washington, DC:National Highway Traffic Safety Administration.

Raoelison, R. N., Koithara, L. L., \& Costil, S. (2021). Computational and Experimental Analysis of the Phenomenological Gas Flow Behavior and Particle Kinematics During Low Pressure Cold Spraying. Thermal Spray 2021: Proceedings from the International Thermal Spray Conference, 83881, 229-234. https://doi.org/10.31399/asm.cp.itsc2021p0229

Reis, R. H. M., Nunes, L. F., da Luz, F. S., Candido, V. S., da Silva, A. C. R., \& Monteiro, S. N. (2021). Ballistic performance of guaruman fiber composites in multilayered armor system and as single target. Polymers, 13(8), 1-15. https://doi.org/10.3390/polym13081203
Selimli, S. (2020). Yüzey Geometrisinin Mermi Aerodinamik Davranışları Üzerine Etkisinin Nümerik İncelenmesi. Journal of Polytechnic, 0900(1), 299-304. https://doi.org/10.2339/politeknik.698872

Tan, P. (2013). Finite element simulation of the behaviours of laminated armour systems against blast wave and projectile dynamic impacts. Proceedings of the Institution of Mechanical Engineers, Part L: Journal of Materials: Design and Applications, 227(1), 2-15. https://doi.org/10.1177/1464420712454371

URL. (2021). Retrieved December 2, 2021, from https://tr.wikipedia.org/wiki/9x19mm_Parabellum

Yanen, C., \& Solmaz, M. (2015). Tabakalı Hibrit Kompozitlerin Bireysel Zirh Malzemesi Olarak Üretimi Ve Balistik Performanslarının İncelenmesi. El-Cezeri Fen ve Mühendislik Dergisi, 2016(2), 351-362. https://doi.org/10.31202/ecjse.67164 